\title{
EDUKASI PENCEGAHAN HIPERTENSI SECARA DARING KEPADA MASYARAKAT RT. 01 DESA ALUH-ALUH BESAR DI MASA PANDEMI
}

\author{
Nita Pujianti'1), Paulus Damar Aji Christanda2), Maudatun Nikmah²), Meisy²) \\ 1)DepartemenAdministrasi dan Kebijakan Kesehatan, Program Studi Kesehatan Masyarakat, Fakultas Kedokteran, \\ Universitas Lambung Mangkurat, Banjarmasin, Kalimantan Selatan, Indonesia \\ 2)Program Studi Kesehatan Masyarakat, Fakultas Kedokteran, Universitas Lambung Mangkurat, Banjarmasin, \\ Kalimantan Selatan, Indonesia \\ Corresponding author : Paulus Damar Aji Christanda \\ E-mail :christandap@gmail.com
}

Diterima 10 Juni 2021, Diterima 01 Juli 2021, Disetujui 03 Juli 2021

\begin{abstract}
ABSTRAK
Hipertensi mendapat julukan silent killer karena menjadi suatu penyakit tanpa gejala. Hipertensi merupakan keadaan peningkatan tekanan darah diatas tekanan darah normal yakni tekanan sistolik $\geq 140 \mathrm{mmHg}$ dan tekanan diastolik $<90 \mathrm{mmHg}$. Metode yang digunakan pada kegiatan pengabdian ini adalah penyuluhan secara daring melalui WhatsApp Group. Kegiatan pengabdian ini bertujuan untuk mengedukasi kepada masyarakat untuk semakin mengetahui mengenai hipertensi, agar nantinya dapat melakukan upaya pencegahan terhadap faktor risiko dari hipertensi. Peserta dalam kegiatan penyuluhan ini sebanyak 11 orang yang merupakan warga Desa Aluh-Aluh Besar RT. 01. Sebelum pemberian materi dilakukan, peserta mengisi pre-test terlebih dahulu dan di akhir kegiatan peserta akan mengisi post-test. Dalam kegiatan edukasi diberikan media audio visual berupa video edukasi dan juga poster yang berisi informasi-informasi yang berkaitan dengan hipertensi.
\end{abstract}

Kata kunci: penyuluhan; hipertensi; daring

\begin{abstract}
Hypertension is nicknamed the silent killer because it is an asymptomatic disease. Hypertension is a state of increased blood pressure above normal blood pressure, namely systolic pressure $140 \mathrm{mmHg}$ and diastolic pressure $<90 \mathrm{mmHg}$. The method used in this service activity is online counseling through WhatsApp Group. This service activity aims to educate the public to know more about hypertension, so that later they can make efforts to prevent risk factors from hypertension. Participants in this counseling activity were 11 people who were residents of Aluh-Aluh Besar Village, RT. 01. Before giving the material, participants fill out the pre-test first and at the end of the activity participants will fill out the posttest. In educational activities, media are provided in the audio-visual form of educational videos and also posters containing information related to hypertension.
\end{abstract}

Keywords: counseling; hypertension; online

\section{PENDAHULUAN}

Hipertensi Hipertensi merupakan keadaan peningkatan tekanan darah diatas tekanan darah normal yakni tekanan sistolik $\geq 140 \mathrm{mmHg}$ dan tekanan diastolik $<90 \mathrm{mmHg}$ (Nugraha et al., 2019). Hipertensi disebut juga sebagai the silent killer yaitu penyakit mematikan tanpa adanya tanda dan gejala terlebih dahulu selama 10-20 tahun dan biasanya baru diketahui apabila telah terjadi komplikasi pada organ target seperti jantung, otak, ginjal dan mata sehingga pengobatannya terlambat dan mengurangi harapan hidup akibat melemahnya fungsi organ-organ tersebut yang berakibat kecacatan bahkan sampai kematian (Oktaviarini et al., 2019).

Berdasarkan data WHO tahun 2015 menunjukkan sekitar 1,13 miliar orang di dunia menyandang hipertensi, artinya 1 dari 3 orang di dunia terdiagnosis hipertensi. Jumlah penyandang hipertensi terus meningkat setiap tahunnya, diperkirakan pada tahun 2025 akan ada 1,5 Miliar orang yang terkena hipertensi, dan diperkirakan setiap tahunnya 9,4 juta orang meninggal akibat hipertensi dan komplikasinya (Arifin et al., 2019). Hasil data Riskesdas tahun 2018 pada penduduk usia 18 tahun keatas menunjukan prevalensi PTM mengalami kenaikan jika dibandingkan dengan tahun 2013, dimana prevalensi hipertensi naik dari 25,8\% menjadi 34,1\%. Kalimantan Selatan menduduki peringkat pertama provinsi yang menderita penyakit hipertensi dengan $44,1 \%$, dimana angka tersebut jauh lebih tinggi dibandingkan dengan rata-rata prevalensi hipertensi secara nasional yaitu sebesar 34,1\% (Maramis et all., 
2020). Berdasarkan data riil penderita hipertensi perkabupaten dan kota di Kalimantan Selatan tahun 2015 yaitu, kota Banjarmasin merupakan tertinggi hipertensi yaitu 18.730 penderita, disusul Tanah Laut sebanyak 14.121 penderita, kemudian Kabupaten Banjar 7.738 penderita, Kotabaru 6.680 penderita, Banjarbaru 5.269 penderita, Tapin 3.085 penderita, Barito Kuala 985 penderita, dan daerah lainnya berkisar antar 1000-2.500 orang penderita (Aryzki et all., 2018).

Gejala yang dialami pada hipertensi adalah dengan adanya peningkatan tekanan darah atau tergantung pada tinggi rendahnya tekanan darah.Gejala hipertensi yang timbul bisa berbeda bahkan terkadang penderita hipertensi tidak memiliki keluhan. Namun karena sering kali penderita hipertensi tidak menyadari adanya gejala, hal tersebut dapat menimbulkan keluhan pada saat sudah terjadinya komplikasi yang spesifik pada organ seperti otak, mata, ginjal, jantung, pembuluh darah, atau organ vital lainnya (Kurniawan dan Sulaiman, 2019).

Beberapa faktor risiko yang dapat menyebabkan hipertensi yaitu faktor yang tidak dapat dimodifikasi antara lain usia lanjut, adanya riwayat tekanan darah tinggi dalam keluarga (genetik), dan jenis kelamin. Faktor yang dapat dimodifikasi antara lain obesitas (kelebihan berat badan) yang iikuti dengan kurangnya olahraga, kebiasaan merokok, konsumsi alkohol, kopi dan makanan yang mengandung natrium (Firmansyah dan Rustam, 2017).

Berdasarkan hasil analisis didapatkan bahwa ada beberapa faktor yang menyebabkan masyarakat di Desa Aluh-Aluh Besar RT.01 menderita penyakit hipertensi diantaranya adalah pola hidup seperi makan makanan asin (ikan asin, konsumsi garam), MSG dan makanan yang berlemak, merokok, konsumsi kafein dan kurangnya aktifivitas fisik seperti berolahraga. Karakteristik tempat tinggal masyarakat Desa Aluh-Aluh RT. 01 umumnya tinggal di didaerah pesisir sungai yang mana mata pencaharian rata-rata ialah nelayan dan bertani sehingga menjadi salah satu faktor masyarakat daerah tersebut sering mengonsumsi makanan asin seperti ikan asin.

Usaha yang dapat dilakukan untuk meningkatkan pemahaman tentang hipertensi yaitu dengan dilakukannya penyuluhan kesehatan. Penyuluhan merupakan suatu upaya yang direncanakan untuk menyebarkan pesan, menanamkan keyakinan, sehingga masyarakat tidak saja sadar, tahu dan mengerti, tetapi juga mau dan bisa melakukan suatu anjuran yang diharapkan untuk meningkatkan status kesehatan, mencegah timbulnya penyakit, mempertahankan derajat kesehatan, memaksimalkan fungsi dan peran penderita selama sakit, dan membantu penderita dan keluarga mengatasi masalah kesehatan (Purwati, 2014)

Berdasarkan hasil penelitian dari Nelwan JE (2019) menyatakan bahwa kegiatan penyuluhan (promosi kesehatan) tentang hipertensi berhubungan dengan peningkatan tingkat pengetahuan. Tindakan mempromosikan kesehatan dalam dua kelompok menunjukkan adanya perbedaan yang signifikan. Dalam konteks ini, pendidikan masyarakat (promosi kesehatan) bisa efektif digunakan terutama untuk pasien kardiovaskular dalam meningkatkan kesehatan, terutama dalam tanggung jawab untuk berperilaku sehat, beraktivitas fisik, dan manajemen stress.

Hipertensi harus dicegah dan ditanggulangi karena hipertensi merupakan faktor risiko utama terjadinya berbagai penyakit kardiovaskuler termasuk stroke, penyakit jantung koroner, gagal jantung, dan penyakit ginjal stadium akhir atau gagal ginjal. Pola hidup yang baik, manajemen stress yang tepat serta olahraga secara teratur merupakan kunci hidup sehat yang dapat mencegah terjadinya hipertensi. Faktor-faktor penyebab hipertensi dapat dihindari dengan salah satu cara yaitu memotivasi masyarakat untuk meningkatkan kualitas hidup sehat dengan menambah pengetahuan serta akses informasi yang cukup (Setiawan et al., 2018). pengetahuan pasien mengenai hipertensi juga berpengaruh pada kepatuhan pasien dalam melakukan pengobatan. Semakin meningkatnya pengetahuan pasien tentang hipertensi maka akan mendorong seseorang untuk berperilaku yang lebih baik dalam mengontrol hipertensi sehingga tekanan darahnya tetap terkendali (Sofiana et al., 2018).

Hipertensi menjadi permasalahan di RT.01 Desa Aluh-Aluh Besar yang datanya telah di dapatkan pada kegiatan PBL I. Namun, dikarenakam pandemi Covid-19 maka intervensi yang sudah direncanakan pada PBL I harus dimodifikasi menjadi penyuluhan melalui Whatsapp mengenai hipertensi dan juga Covid19. Setelah dan sebelum dilakukan intervensi, warga diberikan pre dan post-test melalui google formulir. Kegiatan Pengalaman Belajar Lapangan ini akan fokus pada peningkatan pengetahuan dan kesadaran masyarakat mengenai pencegahan dan pengendalian hipertensi serta pencegahan penularan Covid19. Kegiatan ini dilakukan dengan mengikutsertakan masyarakat secara langsung mulai dari perencanaan hingga evaluasi kegiatan. Sehingga diharapkan agar program 
ini akan terus berlanjut secara swadaya oleh masyarakat meskipun kegiatan Pengalaman Belajar Lapangan telah selesai.

\section{METODE}

Tahap perencanaan dan persiapan dalam melaksanakan kegiatan Pengalaman Belajar Lapangan (PBL) 2 yang dilakukan oleh kelompok 19 RT.01 di Desa Aluh-Aluh Besar dilakukan secara daring. Adapun perencanaan dan persiapan yang dilakukan antara lain sebagai berikut

\section{Perencanaan an persiapan}

Perencanaan (planning) merupakan kegiatan atau proses membuat rencana dengan menetapkan tujuan dan langkah-langkah yang harus dilakukan agar tujuan dapat tercapai. Pada tahap ini, dalam melaksanakan kegiatan Pengalaman Belajar Lapangan (PBL) 2 yang dilakukan oleh kelompok 19 RT.01 di Desa Aluh-Aluh Besar dilakukan secara online/daring. Adapun perencanaan dan persiapan yang dilakukan antara lain sebagai berikut:
a. Mengumpulkan kontak masyarakat sasaran yang akan di intervensi
b. Membuat group whatsapp
c. Rapat persiapan kegiatan
d. Penyusunan prepost, materi dan media yang akan digunakan dalam intervensi
e. Penyusunan Jadwal Kegiatan
1. Pelaksanaan dan proses

Pelaksanaan kegiatan ini di lingkungan Aluh-Aluh Besar RT. 01 Kecamatan Aluh-Aluh, yaitu berupa penyuluhan terkait Hipertensi atau tekanan darah tinggi dengan jumlah peserta sebanyak 11 orang. Kegiatan dilaksanakan melalui WhatsApp Gruop yang dilaksanakan pada tanggal 15-20 November 2020. Dalam kegiatan ini, hari pertama dilakukan pembagian soal pre-test kepada peserta untuk mengetahui seberapa besar pengetahuan peserta tentang materi yang akan disampaikan oleh penyuluh. Setelah seluruh peserta selesai menjawab soal pre-test tersebut, di hari kedua dilanjutkan dengan inti acara yaitu pemberian materi dan video tentang Hipertensi atau tekanan darah tinggi.

Materi yang dibagikan berupa poster, booklet, leaflet dan video mengenai penyebab hipertensi, faktor resionya, serta cara mengatasi dan mengontrol tekanan darah di WhatsApp Grup, pemberian materinya diberikan oleh mahasiswa kelompok 19 agar warga dapat membaca. Setelah dilakukan pemberian media edukasi, penyuluh akan mempersilahkan peserta untuk bertanya mengenai isi dari media yang sudah berikan. Tujuannya agar peserta yang kurang paham dengan materi yang diberikan dapat bertanya, sehingga penyuluh dapat menjelaskan poinpoin yang belum dipahami oleh peserta dari materi tersebut. Diakhirnya diberikan waktu sesi tanya jawab dimana para warga aktif didalam grup terkait pemberian materi.Setelah pemberian materi, hari ketiga dibagikan soal post-test terkait materi yang telah disampaikan oleh penyuluh

\section{Monitoring dan evaluasi}

Monitoring dan evaluasi atau yang disingkat dengan monev merupakan kegiatan yang ditujukan pada suatu program yang sedang atau sudah berlangsung yang bertujua nuntuk melihat perkembangan masyarakat di Desa Alu-aluh Besar RT.01 yang telah dilaksanakan. Monitoring salah satu aktivitas yang dilakukan untuk melihat, memantau jalannya organisasi selama kegiatan berlangsung, dan menilai ketercapaian tujuan, melihat factor pendukung dan penghambat pelaksanaan program. Evaluasi diperlukan untuk mengetahui tingkat perkembangan, kendala maupun permasalahan yang muncul dari terselenggaranya kegiatan. Hasil dari evaluasi juga dapat digunakan sebagai bahan pertimbangan kedepannya sehingga segala bentuk kedepannya dapat diantisipasi (Tristianto, 2018).

Kegiatan monitoring dan evaluasi dilakukan pada saat kegiatan penyuluhan berlangsung dan setelah kegiatan penyuluhan selesai dengan cara melakukan pemantauan dan pengawasan terhadap proses, hasil, dan dampak dari kegiatan penyuluhan ini. Salah satunya adalah menilai apakah pengetahuan dan keterampilan yang telah dimiliki masyarakat dimanfaatkan secara efektif dan efisien

\section{HASIL DAN PEMBAHASAN}

Pada pengambilan data, peneliti membagikan google form dan pengukuran pada responden yaitu sebanyak 11 responden. Setelah dilakukan pengambilan data, kemudian diolah sehingga memperoleh hasil sebagai berikut:

Tabel 1. Hasil Distribusi dan Frekuensi Aspek Pengetahuan Peserta Sebelum dan Sesudah Dilakukan Penyuluhan

\begin{tabular}{ccccc}
\hline $\begin{array}{c}\text { Pengetahuan } \\
\text { tentang Hipertensi }\end{array}$ & \multicolumn{2}{c}{ Sebelum } & \multicolumn{2}{c}{ Sesudah } \\
\cline { 2 - 5 } & $\begin{array}{c}\text { Freku- } \\
\text { ensi }\end{array}$ & $\begin{array}{c}\text { Persen- } \\
\text { tase (\%) }\end{array}$ & $\begin{array}{c}\text { Freku- } \\
\text { ensi }\end{array}$ & $\begin{array}{c}\text { Persen- } \\
\text { tase (\%) }\end{array}$ \\
\hline Baik & 9 & 82 & 10 & 91 \\
\hline Cukup & 2 & 18 & 0 & 0 \\
\hline Kurang & 0 & 0 & 1 & 9 \\
\hline Jumlah & 11 & 100 & 12 & 100 \\
\hline Pada & Tabel & & & \\
& & 1 & menunjukkan
\end{tabular}

menunjukkan bahwa pengetahuan masyarakat 
tentang hipertensi sebelum diberikan penyuluhan tentang hipertensi sebesar $82 \%$ pada kategori baik dan $18 \%$ pada kategori cukup. Setelah dilakukan edukasi, persentase peserta dengan pengetahuan baik meningkat menjadi $91 \%$. Terdapat peningkatan persentase aspek pengetahuan masyarakat mengenai hipertensi. Pertanyaan yang diberikan kepada peserta rata-rata mengalami peningkatan jumlah jawaban benar setelah diberikan edukasi.

Tabel 2. Hasil Distribusi dan Frekuensi Aspek Sikap Peserta Sebelum dan Sesudah Dilakukan Penyuluhan

\begin{tabular}{ccccc}
\hline $\begin{array}{c}\text { Sikap tentang } \\
\text { Hipertensi }\end{array}$ & \multicolumn{2}{c}{ Sebelum } & \multicolumn{2}{c}{ Sesudah } \\
\cline { 2 - 5 } & $\begin{array}{c}\text { Freku- } \\
\text { ensi }\end{array}$ & $\begin{array}{c}\text { Persen- } \\
\text { tase (\%) }\end{array}$ & $\begin{array}{c}\text { Freku- } \\
\text { ensi }\end{array}$ & $\begin{array}{c}\text { Persen- } \\
\text { tase (\%) }\end{array}$ \\
\hline Baik & 3 & 27 & 3 & 27 \\
\hline Cukup & 3 & 27 & 2 & 18 \\
\hline Kurang & 5 & 46 & 6 & 55 \\
\hline Jumlah & 11 & 100 & 11 & 100 \\
\hline
\end{tabular}

Pada Tabel 2 menunjukkan menunjukkan bahwa sikap masyarakat tentang hipertensi sebelum diberikan penyuluhan tentang hipertensi sebesar $27 \%$ pada kategori baik dan cukup, $46 \%$ pada kategori kurang. Setelah dilakukan edukasi, persentase peserta dengan sikap kurang meningkat menjadi $55 \%$. Hal ini dikarenakan masyarakat belum dapat melaksanakan pengetahuan dalam pencegahan hipertensi.

Tabel 3. Hasil Distribusi dan Frekuensi Aspek Tindakan Peserta Sebelum dan Sesudah Dilakukan Penyuluhan

\begin{tabular}{rcccc}
\hline \multirow{2}{*}{$\begin{array}{c}\text { Tindakan tentang } \\
\text { Hipertensi }\end{array}$} & \multicolumn{2}{c}{ Sebelum } & \multicolumn{2}{c}{ Sesudah } \\
\cline { 2 - 5 } & $\begin{array}{c}\text { Freku- } \\
\text { ensi }\end{array}$ & $\begin{array}{c}\text { Persen- } \\
\text { tase (\%) }\end{array}$ & $\begin{array}{c}\text { Freku- } \\
\text { ensi }\end{array}$ & $\begin{array}{c}\text { Persen- } \\
\text { tase (\%) }\end{array}$ \\
\hline Baik & 0 & 0 & 4 & 36.36 \\
\hline Cukup & 6 & 55 & 3 & 27.27 \\
\hline Kurang & 5 & 45 & 4 & 36.36 \\
\hline Jumlah & 11 & 100 & 11 & 100 \\
\hline Pada & Tabel & 3 & menunjukkan
\end{tabular}
menunjukkan bahwa tindakan masyarakat tentang hipertensi sebelum diberikan penyuluhan tentang hipertensi sebesar $55 \%$ pada kategori cukup dan $45 \%$ pada kategori kurang. Setelah dilakukan edukasi, persentase peserta dengan tindakan baik meningkat menjadi $36,36 \%$. Terdapat peningkatan persentase aspek tindakan masyarakat mengenai hipertensi.

Tabel 4. Hasil Analisis Statistik Sebelum dan

\begin{tabular}{cc}
\multicolumn{2}{c}{ Sesudah Diberikan Penyuluhan } \\
\hline Aspek & $\boldsymbol{P}$-value \\
\hline Pengetahun & 0,408 \\
\hline Sikap & 1 \\
\hline Tindakan & 0,230 \\
\hline
\end{tabular}

Berdasarkan hasil uji wilcoxon terhadap hasil pre-post test pengetahuan Hipertensi nilai uji menunjukkan angka 0.408 yaitu lebih dari 0.005 artinya tidak ada perbedaan signifikan antara hasil pre-post test.

Berdasarkan hasil uji T-test terhadap hasil pre-post test sikap terhadap Hipertensi nilai uji menunjukkan angka 1.0 yaitu lebih dari 0.05 artinya tidak ada perbedaan signifikan antara hasil pre-post test.

Berdasarkan hasil uji wilcoxon terhadap hasil pre-post test pengetahuan Hipertensi nilai uji menunjukkan angka 0.230 yaitu lebih dari 0.05 artinya Ho diterima artinya tidak ada perubahan bermakna antara hasil pre-post test.

Kegiatan penyuluhan ini menggunakan media poster, booklet, leftlet dan video. Pada kegiatan ini, media hanya dibagikan dalam format pdf saja dan video edukasi diberikan dalam format video. Sebelum memberikan penyuluhan kepada mayarakat, tahap pertama yang dilakukan ialah pemberian soal pre test melalui google form yang bertujuan untuk mengetahui pengetahuan, sikap dan tindakan masyarakat mengenai penyakit hipertensi.

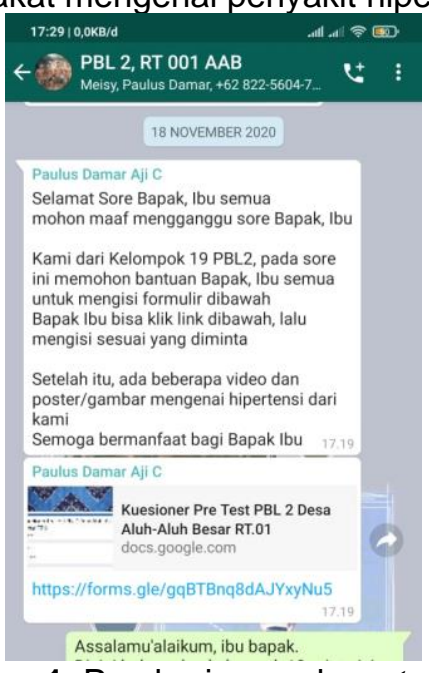

Gambar 1. Pemberian soal pre test kepada peserta

Penyuluhan hipertensi kepada masyarakat dilakukan dengan menggunakan media intervensi berupa poster, leaflet, booklet, serta video. Materi yang diberikan meliputi pengertian, penyebab, faktor risiko, cara menghindari hipertensi, serta pentingnya pemeriksaan tekanan darah. Media poster, leaflet, dan booklet dibuat dengan point-point disertai dengan gambar dan warna yang menarik. Dengan media yang menarik tersebut diharapkan masyarakat memiliki ketertarikan lebih untuk membaca informasi yang disampaikan di dalamnya. 


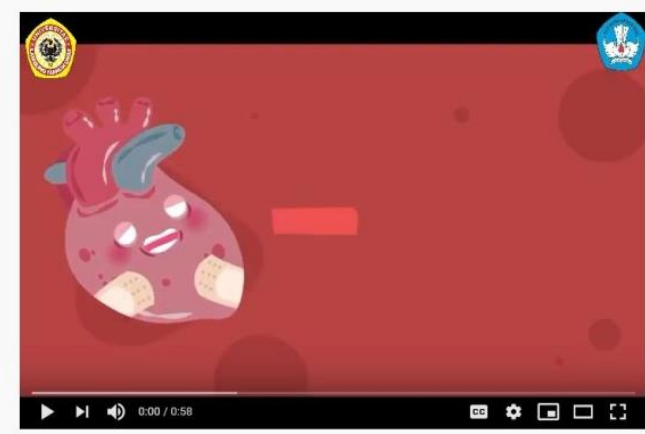

Edukasi Hipertensi_Kelompok 19_Desa Aluh-Aluh Besar RT.01

Gambar 2. Media penyuluhan berupa video edukasi mengenai hipertensi

Video adalah media yang menggabungkan audio, visual dan animasi yang memiliki pesan dan memiliki daya tarik sendiri atau mungkin menjadi pesan persuasif kepada responden. Video berisi persuasive mengenai pengendalian hipertensi. Penelitian yang dilakukan Novaria W, dkk (2019) menyatakan bahwa penggunaan media video mempunyai dampak yang lebih pada penyuluhan kesehatan karena mengandalkan pendengaran dan penglihatan dari sasaran, menarik, pesan yang disampaikan dengan cepat dan mudah diingat dan dapat mengembangkan pikiran (Wijayanti et all., 2019).

Media lainnya yaitu booklet, merupakan berbentuk buku kecil. Ciri dari booklet yaitu buku berukuran kecil dan tipis, berisi informasi yang dilengkapi dengan gambar, dilengkapi penjelasan yang ringkas dan sistematis,berisi informasi pokok tentang hal yang dipelajari sehingga mudah dipahami, ekonomis dalam arti waktu dalammemperolehinformasi, seseorang mendapat informasidengan caranya sendiri (Prasanti dan Ikhsan, 2018). Penelitian oleh Wijayanti dan Mulyadi (2018) menunjukkan bahwa ada pengaruh pendidikan kesehatan menggunakan booklet terhadap pemahaman pasien hipertensi di Puskesmas Kecamatan Pasar Minggu Tahun 2016.

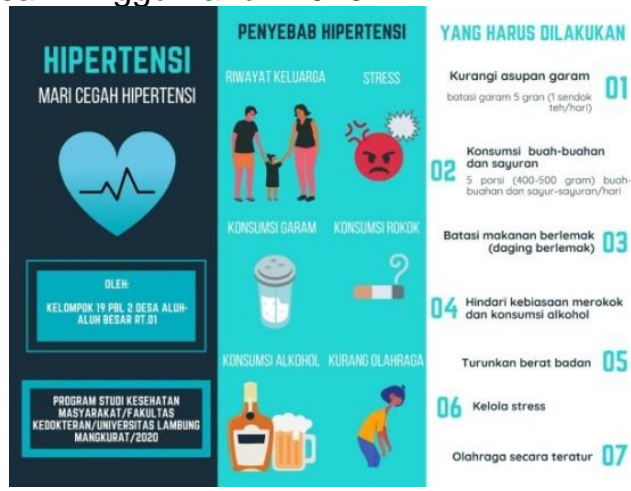

Gambar 3. Media penyuluhan berupa leaflet
Leaflet sendiri merupakan lembaran yang berisikan tentang informasi khusus. Pada isi leaflet tersedia berbagai informasi yang dibutuhkan dan didukung oleh gambar dengan tujuan pembaca dapat memahami langsung isi dari leaflet. Leaflet merupakan salah satu media yang efektif dalam mempengaruhi perilaku seseorang (Susanti et all., 2017). Sedangkan poster sendiri merupakan media yang berisikan gambar dan sedikit kata-kata. Kata-kata dalam poster harus jelas artinya, tepat pesannya, dan dapat dengan mudah dibaca (Prasanti dan Ikhsan, 2018).

Berdasarkan hasil pre-pos tes yang sudah ditunjukan oleh tabel-tabel di atas, serta dilakukan uji normalitas dan uji wilcoxon. Dilihat dari dari aspek pengetahuan, terdapatnya peningkatanpengetahuan sebelum (pre) dan sesudah (pos) diberikan promosi kesehatan. Hal ini berarti pemberian promosi kesehatan bisa meningkatkan pengetahuan. Pengetahuan merupakan kemampuan seseorang untuk memutuskan tindakan apa yang akan dilakukan (Hanum et all., 2019). Pengetahuan penderita hipertensi sangat berpengaruh pada sikap untuk patuh berobat. Semakin tinggi pengetahuan maka keinginan untuk patuh berobat juga semakin meningkat sehingga penyakit komplikasi yang akan ditimbulkan akan menurun (Nelwan, 201). hal ini sejalan dengan hasil penelitian Yulianis $\mathrm{Y}$, dkk tahun 2020 menyatakan bahwa adanya pengaruh penyuluhan kesehatan sebelum dan sesudah terhadap tingkat pengetahuan masyarakat (Yulianis et all., 2020).

Saputro tahun 2009 menyatakan bahwa terdapat hubungan yang bermakna antara tingkat pengetahuan pasien dengan kepatuhan minum obat, hal ini dapat berkaitan dengan aspek sikap responden, dimana jika tingkat pengetahuan respoenden meningkat pula tindakan responden untuk meminum obat juga meningkat dapat dilihat dengan adaya peningkatan rerata pre dan pos-test di aspek tindakan (Hanum et all., 2019). Sejalan degan pendapat Sari tahun 2016 bahwa pengetahuan dan sikap menjadi faktor kepatuhan seseorang dalam minum obat (Ulya et all., 2017).

Sikap dapat mempengaruhi tindakan kesehatan serta minat atau kemauan untuk bertindak positif yang akan menghasilkan tidakan kesehatan yang positif pula. Pembentukan sikap dipengaruhi oleh beberapa faktor yaitu pengalaman pribadi, kebudayaan, orang lain yang dianggap penting, media massa, institusi atau lembaga pendidikan atau agama, serta emosi yang ada didala diri seseorang 


\section{SIMPULAN DAN SARAN}

Kegiatan pengalaman Belajar Lapangan yang dilaksanakan di Desa AluhAluh Besar RT 01 Kecamatan Aluh-Aluh ini dilaksanakan secara daring melalui WhatsApp Group. Adapun untuk pembahasan yang diambil adalah terkait Hipertensi. Sebelum disampaikan materi, peserta diberikan pre-test terlebih dahulu. Setelah semua materi disampaikan kemudian diberikan post-test untuk melihat ada tidaknya perubahan nilai pengetahuan, sikap dan perilaku peserta. Dengan hasil pengetahuan peserta penyuluhan mengalami peningkatan namun tidak signifikan. Sikap peserta setelah diberikan penyuluhan mengalami perubahan tetapi tidak signifikan. Sedangkan perilaku peserta penyuluhan mengalami peningkatan namun tidak signifikan. Diharapkan kepada peserta agar pengetahuan yang didapatkan dalam kegiatan pengabdian ini dapat diterapkan dalam kehidupan sehari-hari agar terhindar dari dampak yang muncul akibat hipertensi. Selainitu, proses penyampaian pesan atau informasi dalam kegiatan penyuluhan dengan menggunakan media harus jelas, menarik dan interaktif, sehingga dapat meningkatkan kualitas pesan yang disampaikan.

\section{UCAPAN TERIMAKASIH}

Kegiatan pengalaman belajar lapangan (PBL) 2 ini tidak akan berlaksana dengan baik, tanpa adanya dukungan dari berbagai pihak di dalamnya, mulai dari pihak Universitas Lambung Mangkurat, Program Studi Kesehatan Masyarakat, Pemerintahan daerah Kabupaten Banjar, Aparat Desa Aluh-Aluh Besar, dan masyarakat setempat khuusnya masyarakat Desa Aluh-Aluh Besar RT.01. Untuk itu, kami dari tim Pengalaman Belajar Lapangan (PBL) menyucapkan terima kasih kepada pihakpihak yang telah yang turut berpartisipasi dalam kegiatan ini

\section{DAFTAR RUJUKAN}

Arifin RF, Ritna U, I Made M. (2019). Faktorfaktor yang berhubungan terhadap tingkat hipertensi pada lansia. Jurnal Darul Azhar 8 (1) $81-86$.

Aryzki S dkk. (2018). Evaluasi rasionalitas pengobatan hipertensi di Puskesmas Pelambuan Banjarmasin tahun 2017. Jurnal IImiah Manuntung, 4(2), 119-128.

Firmansyah MR, Rustam. (2017) Hubungan merokok dan konsumsi kopi dengan tekanan darah pada pasien hipertensi Jurnal Kesehatan, 8(2), 263-268.

Hanum S, Puetri, NR, Marlinda, M, \& Yasir, Y. (2019). Hubungan antara pengetahuan, motivasi, dan dukungan keluarga dengan kepatuhan minum obat pada penderita hipertensi di Puskesmas Peukan Bada Kabupaten Aceh Besar. Jurnal Kesehatan Terpadu (Integrated Health Journal), 10(1), 30-35.

Kurniawan, I., \& Sulaiman. (2019). Exercise Relationships, Stress and Eating Patterns with Hypertension Levels in Posyandu Lansia In Sudirejo Village I Sub District Medan City. Jhsp, 1(1), 10-17.

Manuntung A. (2018). Terapi kognitif pada pasien hipertensi. Malang: Wineka Media.

Maramis NM, Grace DK, Jeini EN. (2020). Apakah kebiasaan merokok dan konsumsi minuman beralkohol berhubungan dengan kejadian hipertensi?. Journal of Public Health and Community Medicine, 1(1), 128-134.

Mardhiah A, dkk. (2020). Pendidikan kesehatan dalam peningkatan pengetahuan, sikap dan keterampilan keluarga dengan hipertensi - Pilot Study. Jurnal Ilmu Keperawatan, 3 (2), 111-121.

Nelwan JE. (2019). Pengaruh penyuluhan kesehatan terhadap perubahan pengetahuan masyarakat tentang hipertensi di Kota Manado. Journal Public Health Without Border, 1 (2), 1-15.

Nugraha Y, Niniek H, Prasetyo H. (2019). Peningkatan pengetahuan konsumsi garam harian dan deteksi dini hipertensi pada lansia di Cinere. Abdamas, 1 (1), 223-228.

Oktaviarini E, Soeharyo H, Shofa C. (2019). Beberapa faktor yang beirisko terhadap hipertensi pada pegawai di Wilayah Perimeter pelabuhan (studi di kantor Kesehatan Pelabuhan Kelas II Semarang). Jurnal Epidemiologi Kesehatan Komunitas, 4 (1), 35-44.

Prasanti D, Ikhsan F. 2018. Pemanfaatan media komunikasi dalam penyebaran informasi kesehatan kepada masyarakat. REFORMASI 8(1): 8-14.

Purwati, R. D., Bidjuni, H., \& Babakal, A. (2014). Pengaruh penyuluhan kesehatan terhadap pengetahuan perilaku klien hipertensi di puskesmas bahu manado. Jurnal Keperawatan, 2(2).

Sari ID, Mubasyiroh R, Supardi S. (2016). Hubungan pengetahuan dan sikap dengan kepatuhan berobat pada pasien TB paru yang rawat jalan di Jakarta tahun 2014. Media Penelitian dan Pengembangan Kesehatan, 26 (4), 243248.

Setiawan, H., Suhanda, S., Rosliati, E., Firmansyah, A., \& Fitriani, A. (2018). Promosi Kesehatan Pencegahan Hipertensi Sejak Dini. ABDIMAS: Jurnal 
Pengabdian Masyarakat, 1(2), 41-45. https://doi.org/10.35568/abdimas.v1i2.38

Sofiana, L., Puratmadja, Y., Sari, B. S. K., Pangulu, A. H. R., \& Putri, I. H. (2018). Pengetahuan Tentang Hipertensi Melalui Metode Penyuluhan. Jurnal Pemberdayaan: Publikasi Hasil Pengabdian Kepada Masyarakat, 2(1), 171. https://doi.org/10.12928/jp.v2i1.443

Susanti N, dkk. (2017). Efektifitas leaflet terhadap pengetahuan dan mengatur pola makan lansia penderita hipertensi di Puskesmas Serasan Kabupaten Natuna. Jurnal Photon 7(2): 33-38.

Syfael AB, Fatimah A. (2020). Hubungan pengetahuan, sikap dan perilaku dengan kepatuhan ibu rumah tangga dalam pencegahan Covid-19 di RT 02 RW 05 Kabandungan I Desa Sirnagalih Bogor. Jurnal Program Mahasiswa Kreatif, 4(1): 112-123.

Tristianto, C. (2018). Penggunaan metode waterfall untuk pengembangan sistem monitoring dan evaluasi pembangunan pedesaan. In ESIT 12 (1), 8-22.

Ulya Z, dkk. (2017). Pengaruh pendidikan kesehatan dengan media poster terhadap pengetahuan manajemen hipertensi pada penderita hipertensi. Jurnal Keperawatan Soedirman, 12 (2), 38-46.

Wijayanti, N., Triyanta, \& Ani, N. (2019). Efektifitas Penyuluhan Kesehatan Sadari Dengan Media Video Terhadap Pengetahuan Pada Remaja Putri Di Smk Muhammadiyah Cawas Klaten Effectiveness Of Sadari Health Education Using Video On Adolescent Girls Knowledge In Muhammadiyah Cawas Klaten Vocational $H$. Jurnal IImu Kesehatan Masyarakat Berkala, 1(1), 4958.

Yulianis Y, Fauziah AU, Kusumawati D. (2020). Informasi kesehatan melalui penyuluhan, poster dan leaflet di Dusun Talang Parit Desa Kemingking Dalam Kecamatan Taman Rajo Provinsi Jambi. Jurnal Abdimas Kesehatan (JAK), 2 (2), 157-162. 